\title{
Correlation between the Track Density and Absorbance of Alpha Particles using CR-39 Detectors from UV-Visible Spectrum
}

\author{
Ali Abdulwahab Ridha, ${ }^{*}$ Nada Farhan Kadhim and Nadheer Jasim Mohammed \\ Physics Department, College of Science, \\ Mustansiriyah University, 10052 Baghdad, Iraq \\ *Corresponding author: dr.ali@uomustansiriyah.edu.iq
}

Published online: 25 August 2019

To cite this article: Ridha, A. A., Kadhim, N. F. \& Mohammed, N. J. (2019). Correlation between the track density and absorbance of alpha particles using CR-39 detectors from UV-visible spectrum. J. Phys. Sci., 30(2), 37-49, https://doi.org/10.21315/jps2019.30.2.3

To link to this article: https://doi.org/10.21315/jps2019.30.2.3

\begin{abstract}
A significant correlation between the track density measured by CR-39 and the affluence has been found in the current study. This correlation can be used to calculate the expected track density in solid state nuclear track detector irradiated by any alpha source of known activity without using the detectors. Nine pieces of CR-39 were irradiated with alpha particles from Am-241 (10 $\mu \mathrm{Ci}$ ) point source for $0 \mathrm{~s}, 10 \mathrm{~s}, 20 \mathrm{~s}$, $30 \mathrm{~s}, 40 \mathrm{~s}, 50 \mathrm{~s}, 60 \mathrm{~s}, 70 \mathrm{~s}$ and $80 \mathrm{~s}$. The absorbance in $U V$-visible region (before and after etching of the detector) and in the energy band gap showed an acceptable correlation at $650 \mathrm{~nm}$ wavelength. This result leads to two semi-empirical equations: first equation between the track density and the absorbance; and second equation between the absorbance and the affluence. These findings can give the track density or the affluence by calculating the absorbance of the detector after etching without microscopic viewing and calibration.
\end{abstract}

Keywords: Semi-empirical equation, UV-visible spectrometer, alpha irradiation, CR-39, track density

\section{INTRODUCTION}

The interaction of ionising radiation with polymers causes electronic ionisation in the material, which leads to breaking of molecular bonds and formation of free radicals. The free radicals are associated with scission and cross linking for the molecular chains. ${ }^{1,2}$ As a consequence, the physio-chemical properties like optical, electrical, mechanical and chemical and track properties of the polymer are modified. ${ }^{1}$ 
As radiation is one of the important factors that change the structural characteristics of polymers, it would be useful to study the alterations of thermal and optical properties due to irradiation. ${ }^{3}$

When CR-39 is exposed to alpha particles, it creates a latent damage path due to low linear energy transfer. Irradiation of the track detectors yields crosslinking and chain scission, which will reduce the etch rate. If the probability of crosslinking reaction is larger than chain scission, the substance would become hardened. In chain scission process, emission of atoms and molecules $\left(\mathrm{CO}, \mathrm{CO}_{2}\right.$ and $\left.\mathrm{H}_{2}\right)$ happens as a result of the cut in the long chain. This method softens the material which increases etch rate. ${ }^{4}$

The passing of alpha particles within CR-39 sample produces ionisation for almost all atoms closed to its path. This initial ionising process triggers a set of new chemical processes that result in the formulation of free chemical radicals and other chemical species. ${ }^{5}$ A region enriched with free radicals and other chemical species can create a damage zone along the path of the alpha particle, which is called a latent track. The latent track can be shown through the chemical etching (erosion) in the material surface by applying an acid or a base solvent. ${ }^{5,6}$

The effectiveness of those differences depends upon the formation of the polymer and the laboratory conditions of irradiation such as energy and affluence. Studying the chemical modifications may enhance their applications in different areas, e.g., for the measurement of high radiation doses. ${ }^{\text {? }}$

\section{THEORETICAL AND EXPERIMENTAL}

Nine pieces of CR-39 nuclear track detector polymer sheets of $1 \mathrm{~cm}^{2}$ area, with a thickness of $490 \mu \mathrm{m}$, and density of $1.32 \mathrm{gm} \mathrm{cm}^{-3}$ (Pershore Ltd., United Kingdom), with the chemical formula $\mathrm{C}_{12} \mathrm{H}_{18} \mathrm{O}_{7}$ were used in this study. Eight pieces of CR39 were exposed to alpha particles emitted from Americium (Am-241). The activity of Americium point source is $10 \mu \mathrm{Ci}(370000 \mathrm{~Bq})$ in $10-1-1981$ to become $9.44 \mu \mathrm{Ci}(349284 \mathrm{~Bq})$ at the time of measurement (14-12-2016) for different periods of time exposure at $10 \mathrm{~s}, 20 \mathrm{~s}, 30 \mathrm{~s}, 40 \mathrm{~s}, 50 \mathrm{~s}, 60 \mathrm{~s}, 70 \mathrm{~s}$ and $80 \mathrm{~s}$. One piece was used as a control sample without any exposure to be used as a zero radiation background for measuring the spectra of $\mathrm{UV}$-visible. The main emitted alpha particles energy from the source was $5.486 \mathrm{MeV}$. However, the energy was reduced by placing the detector at a distance of $2 \mathrm{~mm}$ from the source to be 4.752 MeV. The kinetic energy was calculated by the Stopping and Range of Ions in Matter (SRIM) code. The incident flux ( $\varphi$ ) of the source $\left(694878 \alpha \mathrm{s} \mathrm{s}^{-1} \mathrm{~cm}^{-2}\right)$ was calculated from the following equation: ${ }^{8}$ 


$$
\varphi=\mathrm{A}_{\mathrm{c}} / 4 \pi \mathrm{r}^{2}
$$

where $A_{c}$ is the activity of the source in $(B q)$ or $\left(\alpha\right.$-particle $\left.s^{-1}\right)$, and $r$ is the sourcedetector distance in $\mathrm{cm}$. The affluence $(\Phi)$ in unit $\left(\alpha\right.$-particle $\left.\mathrm{cm}^{-2}\right)$ of the source for a certain irradiation time $(\mathrm{t})$ can also be calculated from the following equation: ${ }^{6}$

$$
\Phi=\varphi \mathrm{t}
$$

Track densities for the pristine and the exposed CR-39 detectors are calculated from Equation 3, after etching them chemically in $\mathrm{NaOH}$ solution at $6.25 \mathrm{~N}$ for $5 \mathrm{~h}$ at a temperature of $60^{\circ} \mathrm{C}$. The number of tracks was computed by viewing them with an optical microscope at a magnification of $400 \mathrm{X}$.

$$
\rho(\text { track density })=\text { average number of tracks/field of view }
$$

Optical properties of the CR-39 sheets in the wavelength range 200-800 nm were carried out using the UV-visible spectrophotometer to measure the spectral studies in UV-visible region. The optical absorption coefficient $\left(\alpha_{v}\right)$ at the corresponding wavelengths was calculated using the Beer-Lambert's relation as in the following equation: ${ }^{9}$

$$
\alpha_{v}=(2.303 \mathrm{~A}) / 1
$$

where $\mathrm{A}$ is the absorbance after correction for reflection losses, 1 is the path length of the quartz cuvette $(\mathrm{cm})$ or the sheet thickness in our research which is $490 \mu \mathrm{m}$, and $\mathrm{A}$ is the logarithm of the transmitted to incident beam of light $\mathrm{A}=\log \left(\mathrm{I} / \mathrm{I}_{\mathrm{o}}\right)$. The optical energy band gap $\left(\mathrm{E}_{\mathrm{g}}\right)$ of the detectors was calculated using the following equation: ${ }^{4}$

$$
\alpha_{v} \cdot h v=B\left(h v-E_{g}\right)^{n}
$$

where $\alpha_{v}$ is the absorption coefficient, $h v$ is the photon energy $(\mathrm{eV}), \mathrm{B}$ is an energy independent constant (band tailing parameter), $\mathrm{E}_{\mathrm{g}}$ is the optical energy band gap $(\mathrm{eV})$ of the nanoparticles and $\mathrm{n}$ is a number that features the transition process which takes values of $1 / 2,1,2$ or $3 / 2$ depending on the nature of the electronic transitions responsible for the absorption $(n=1 / 2)$ for direct band gap and 2 for indirect band gap transitions. 


\section{RESULTS AND DISCUSSION}

\subsection{Nuclear Calculations}

Nuclear tracks in the studied detectors were shown in Figure 1. It is very clear that any increase in the number of tracks was due to increase in the time of irradiation. Nuclear calculations, affluence and the track density before and after etching have been calculated from Equations 2 and 3 respectively for each time of irradiation and listed in Tables 1 and 2.

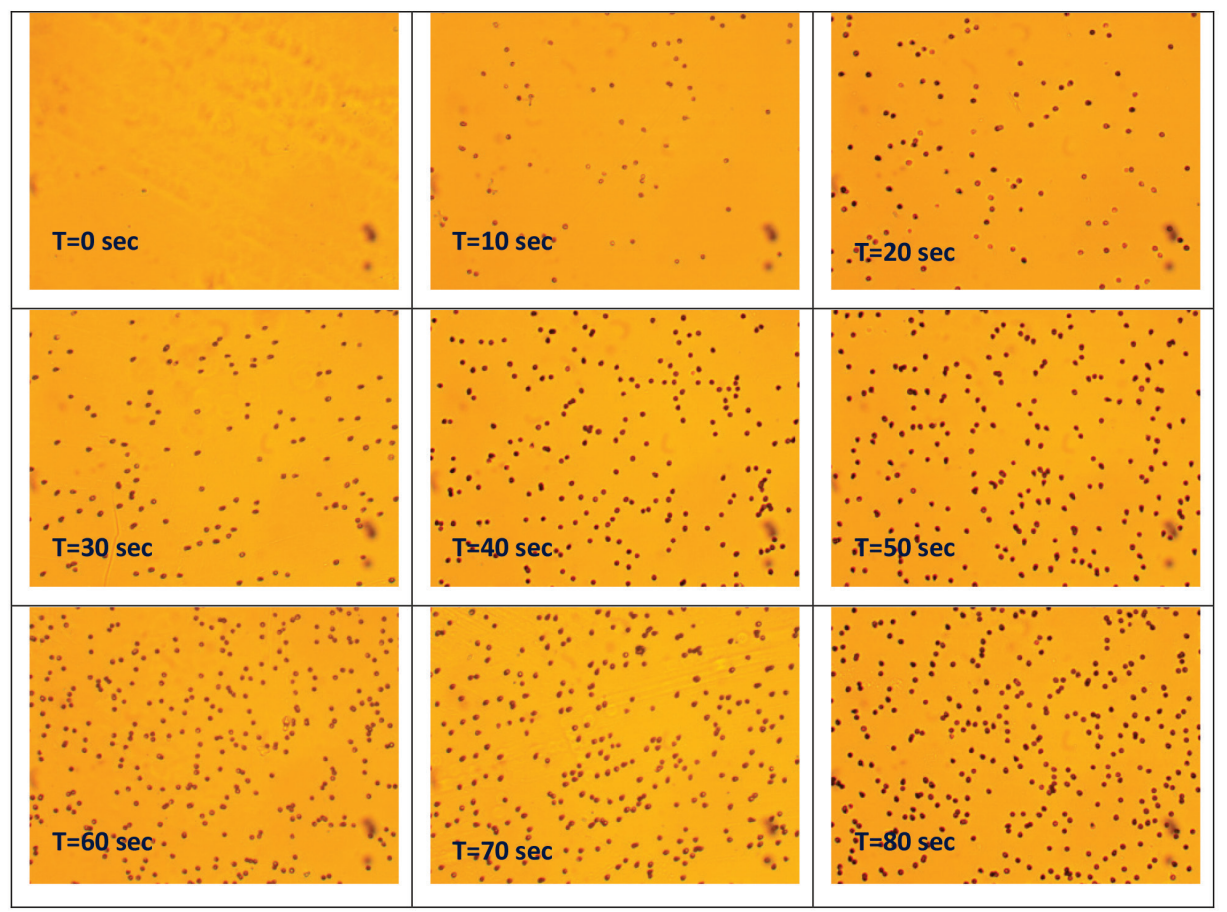

Figure 1: The relationship between the tracks in the CR-39 detectors and duration of irradiation exposure time. 
Table 1: Irradiation time, affluence, track density, absorbance and energy gap for the CR-39 detectors before etching at various irradiation times.

\begin{tabular}{clcccccc}
\hline \multirow{2}{*}{$\begin{array}{c}\text { Irradiation } \\
\text { time }(\mathrm{s})\end{array}$} & $\begin{array}{l}\text { Affluence } \\
(\Phi)\left(\alpha \mathrm{cm}^{-2}\right)\end{array}$ & $\begin{array}{c}\text { Track density } \\
(\rho)\left(\alpha \mathrm{cm}^{-2}\right)\end{array}$ & \multicolumn{4}{c}{$\begin{array}{c}\text { Absorbance }(\mathrm{A} \%) \text { at chosen } \\
\text { wavelengths }(\mathrm{nm})\end{array}$} & $\begin{array}{c}\text { Energy } \\
\text { gap }(\mathrm{eV})\end{array}$ \\
\hline 0 & 0 & 167 & 0.584 & 0.311 & 0.049 & 0.099 & 4.589 \\
10 & 6948780 & 1017 & 0.739 & 0.299 & 0.067 & 0.068 & 4.594 \\
20 & 13897560 & 1750 & 0.648 & 0.296 & 0.072 & 0.097 & 4.692 \\
30 & 20846340 & 2417 & 0.705 & 0.295 & 0.069 & 0.062 & 4.621 \\
40 & 27795120 & 3267 & 0.497 & 0.276 & 0.065 & 0.049 & 4.726 \\
50 & 34743900 & 3950 & 0.707 & 0.28 & 0.067 & 0.079 & 4.722 \\
60 & 41692680 & 4383 & 0.812 & 0.294 & 0.083 & 0.045 & 4.709 \\
70 & 48641460 & 5033 & 0.648 & 0.304 & 0.073 & 0.049 & 4.758 \\
80 & 55590240 & 5650 & 0.649 & 0.3045 & 0.075 & 0.044 & 4.800 \\
\hline
\end{tabular}

Table 2: Irradiation time, affluence, track density, absorbance and energy gap for the CR-39 detectors after etching.

\begin{tabular}{|c|c|c|c|c|c|c|c|}
\hline \multirow{2}{*}{$\begin{array}{l}\text { Irradiation } \\
\text { time }(s)\end{array}$} & \multirow{2}{*}{$\begin{array}{l}\text { Affluence } \\
(\Phi) \\
\left(\alpha \mathrm{cm}^{-2}\right)\end{array}$} & \multirow{2}{*}{$\begin{array}{l}\text { Track density } \\
\text { ( } \rho)\left(\alpha \mathrm{cm}^{-2}\right)\end{array}$} & \multicolumn{4}{|c|}{$\begin{array}{c}\text { Absorbance }(\mathrm{A} \%) \text { at chosen } \\
\text { wavelengths }(\mathrm{nm})\end{array}$} & \multirow{2}{*}{$\begin{array}{l}\text { Energy } \\
\text { gap }(\mathrm{eV})\end{array}$} \\
\hline & & & 280 & 300 & 355 & 650 & \\
\hline 0 & 0 & 167 & 0.567 & 0.328 & 0.063 & 0.044 & 4.671 \\
\hline 10 & 6948780 & 1017 & 0.871 & 0.324 & 0.08 & 0.051 & 4.689 \\
\hline 20 & 13897560 & 1750 & 0.573 & 0.336 & 0.08 & 0.057 & 4.658 \\
\hline 30 & 20846340 & 2417 & 0.609 & 0.36 & 0.084 & 0.059 & 4.712 \\
\hline 40 & 27795120 & 3267 & 0.706 & 0.336 & 0.087 & 0.064 & 4.714 \\
\hline 50 & 34743900 & 3950 & 0.659 & 0.428 & 0.088 & 0.066 & 4.707 \\
\hline 60 & 41692680 & 4383 & 0.571 & 0.339 & 0.089 & 0.073 & 4.69 \\
\hline 70 & 48641460 & 5033 & 0.601 & 0.367 & 0.111 & 0.094 & 4.71 \\
\hline 80 & 55590240 & 5650 & 0.645 & 0.407 & 0.149 & 0.131 & 4.708 \\
\hline
\end{tabular}

\subsection{Optical Calculations}

The absorption spectra of the detectors were recorded using UV-visible spectrophotometer in the wavelength range $200-800 \mathrm{~nm}$ before and after etching. 


\subsubsection{Absorbance at ultraviolet region}

The absorbance in UV region for CR-39 detectors before and after etching was illustrated in spectra 2 and 3 (Figures 2 and 3) which can be distinctive into three parts depending on convergence or divergence in the absorption lines of the detectors. Three wavelengths $(280 \mathrm{~nm}, 300 \mathrm{~nm}$ and $355 \mathrm{~nm})$ were chosen to denote them as seen in Tables 1 and 2. The absorbance difference of the detectors has fluctuated due to increase in time of irradiation in particular at $280 \mathrm{~nm}$, and almost constant at $300 \mathrm{~nm}$, while increasing at $355 \mathrm{~nm}$. However, there is no relationship between the track density or affluence and the absorbance in the regression line. The variation in absorbance relative to increase in the affluence at $355 \mathrm{~nm}$ may be due to the production of the chain scission in CR-39 after irradiation. In case of lower affluence at $300 \mathrm{~nm}$ wavelength, the ion entrapments were predominant and produce local charge lead to a subsequent decrease in the absorbance.

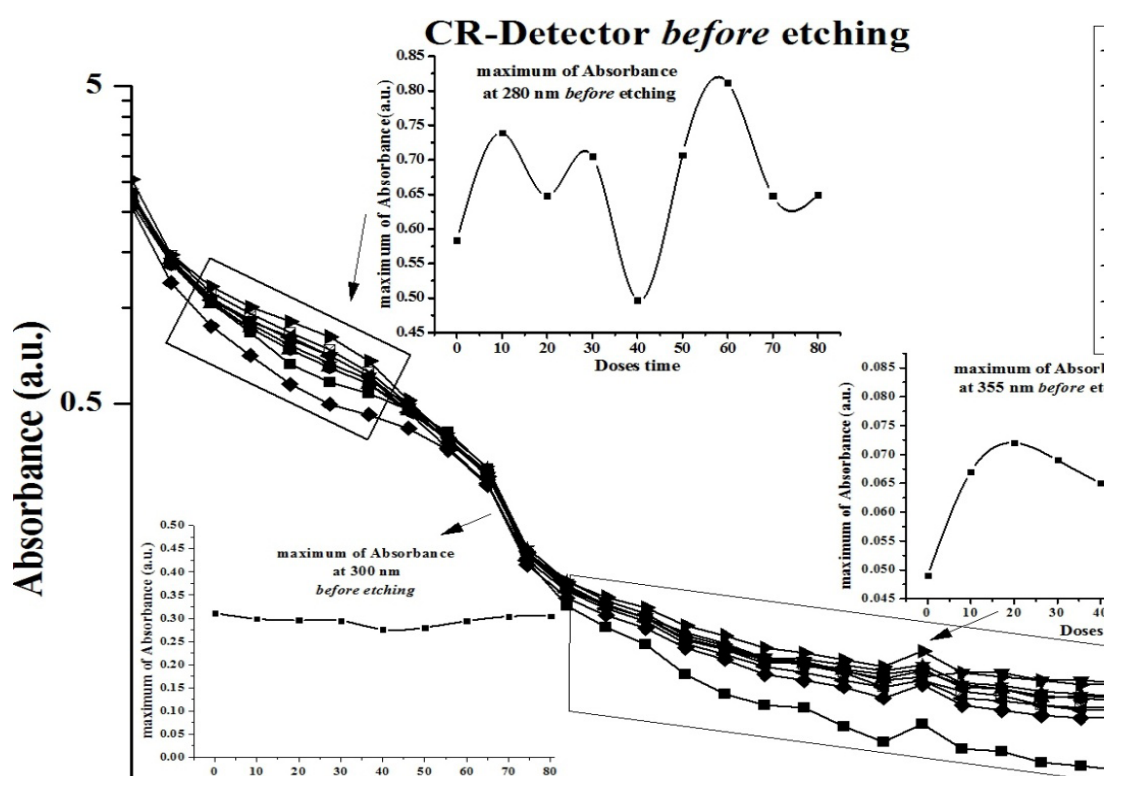

Figure 2: Spectrum between wavelength and absorbance in UV region for the detectors before etching. 


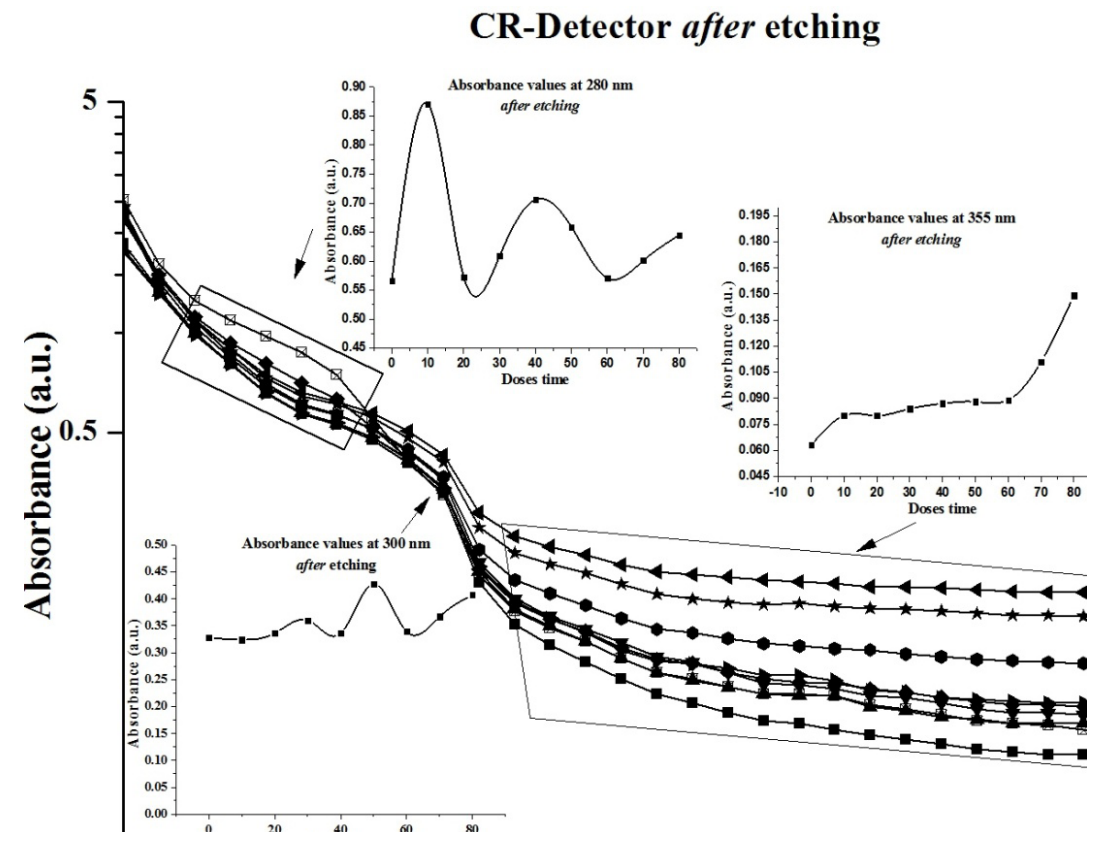

Figure 3: Spectrum between wavelength and absorbance in UV region for the detectors after etching.

\subsubsection{Absorbance at visible region}

The absorbance spectra in the visible region for the detectors before and after etching are shown in Figures 4 and 5, respectively. At $650 \mathrm{~nm}$, the results showed a significant fluctuation in the absorbance spectra in relation to the time of irradiation before etching the detectors (Figure 4). Figure 5 shows a positive correlation at $650 \mathrm{~nm}$ wavelength after etching. Therefore, it can derive an accurate correlation between absorbance and affluence or absorbance and track density after etching the detector. 


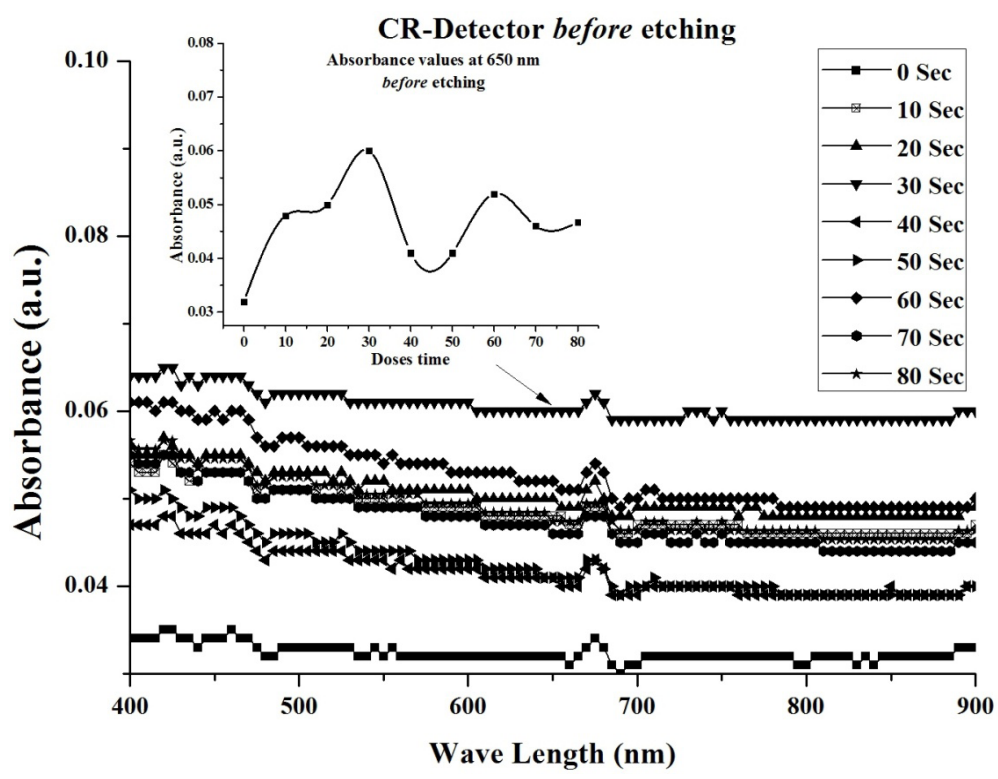

Figure 4: Spectrum between wavelength and absorbance in visible region before etching the detectors.

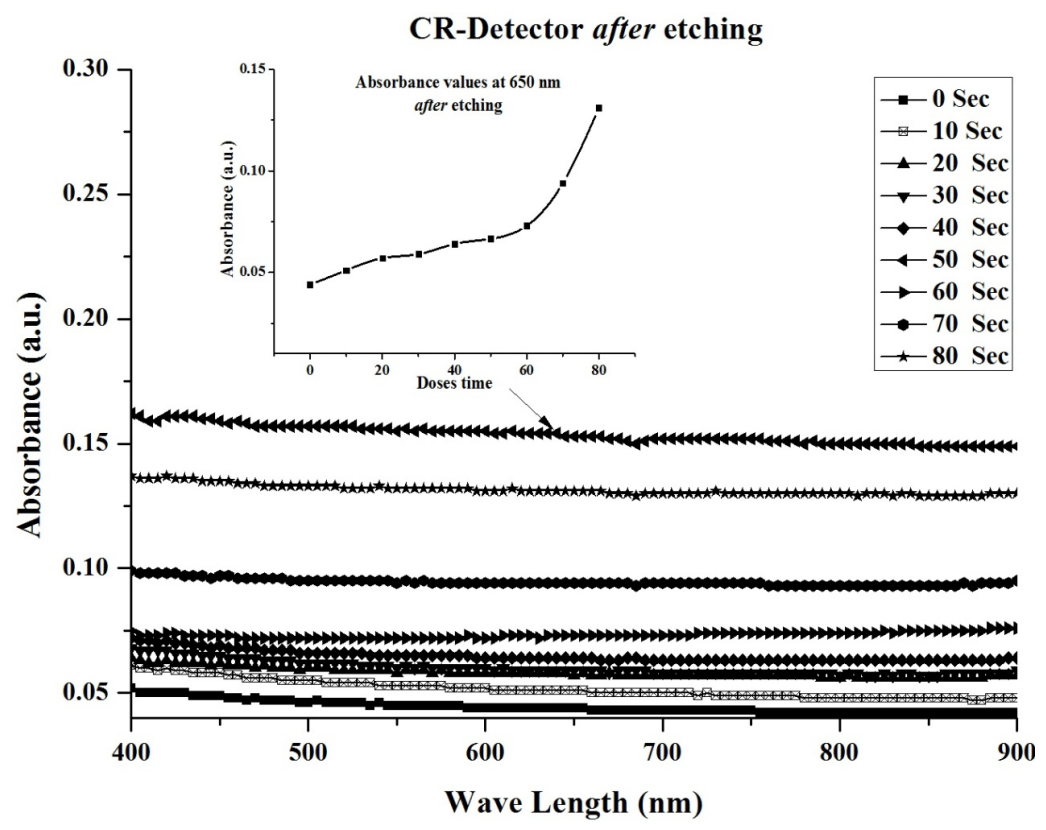

Figure 5: Spectrum between wavelength and absorbance in visible region after etching the detectors. 


\subsubsection{Optical energy band gap}

The optical energy gap was calculated from Equations 4 and 5 before and after etching of the detectors as shown in Figures 6 and 7, respectively. Figure 6 shows that the energy gap was increased from 4.589 at zero $\mathrm{s}$ time of irradiation to 4.824 at $80 \mathrm{~s}$, while it remained almost constant after etching (Figure 7). However, there was no clear correlation between the energy gap and the affluence or the rack density (Figures 6 and 7). Figure 8 shows that there is a linear relationship between the measured track density and the calculated affluence which can be expressed by a first semi-empirical equation with highly significant correlation coefficient $\left(\mathrm{R}^{2}=0.995\right) \%$, shown in Figure 8 . The following equation was derived from the relationship between the measured track density and the calculated affluence:

$$
\rho=0.0001 \Phi+351.84
$$

where $\rho$ is the track density in unit of $\alpha$-tracks $/ \mathrm{cm}^{2}$ and $\Phi$ is the affluence of alpha particles in unit $\alpha \mathrm{cm}^{-2}$ or Bq.s cm $\mathrm{cm}^{-2}\left(\mathrm{~Bq}=\alpha \mathrm{s}^{-1}\right)$.

The second correlation between affluence and absorbance at $650 \mathrm{~nm}$ after etching has a polynomial fitting in order 3 with $\mathrm{R}^{2} 0.971$ (Figure 9) and described below:

$$
\Phi=8 \times 10^{10} \mathrm{~A}^{3}-3 \times 10^{10} \mathrm{~A}^{2}+4 \times 10^{9} \mathrm{~A}-1 \times 10^{8}
$$

where $\Phi$ is the affluence of alpha particles in $\alpha \mathrm{cm}^{-2}$ or Bq.s $\mathrm{cm}^{-2}$ and $\mathrm{A}$ is the absorbance get in the detector. The other important semi-empirical equation was the polynomial correlation in order 3 again. It was derived to describe the relationship between the track density and the absorbance at $650 \mathrm{~nm}$ after etching with $\mathrm{R}^{2}=0.971$ (Figure 10). The equation is described in the following:

$$
\rho=1 \times 10^{7} \mathrm{~A}^{3}-5 \times 10^{6} \mathrm{~A}^{2}+564863 \mathrm{~A}-16902
$$

where $\rho$ is the track density in $\alpha \mathrm{cm}^{-2}$ and $\mathrm{A}$ is the absorbance in the detector. 


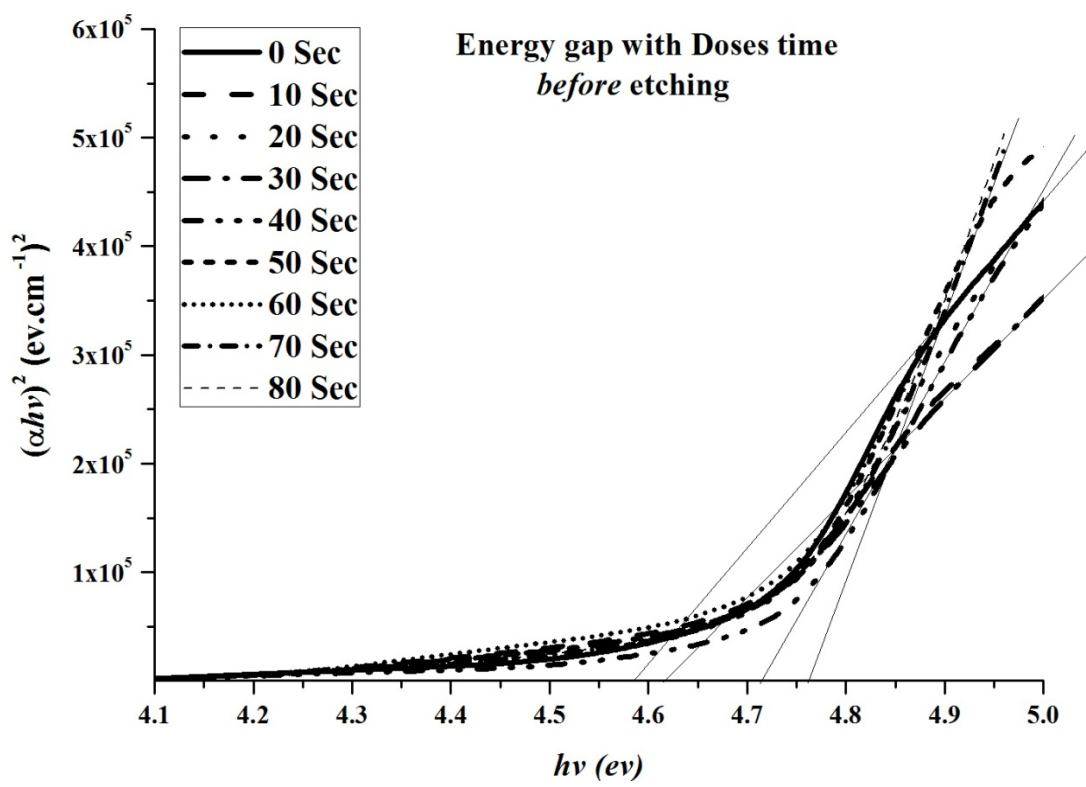

Figure 6: Optical energy gap of the pristine and the irradiated detectors before etching.

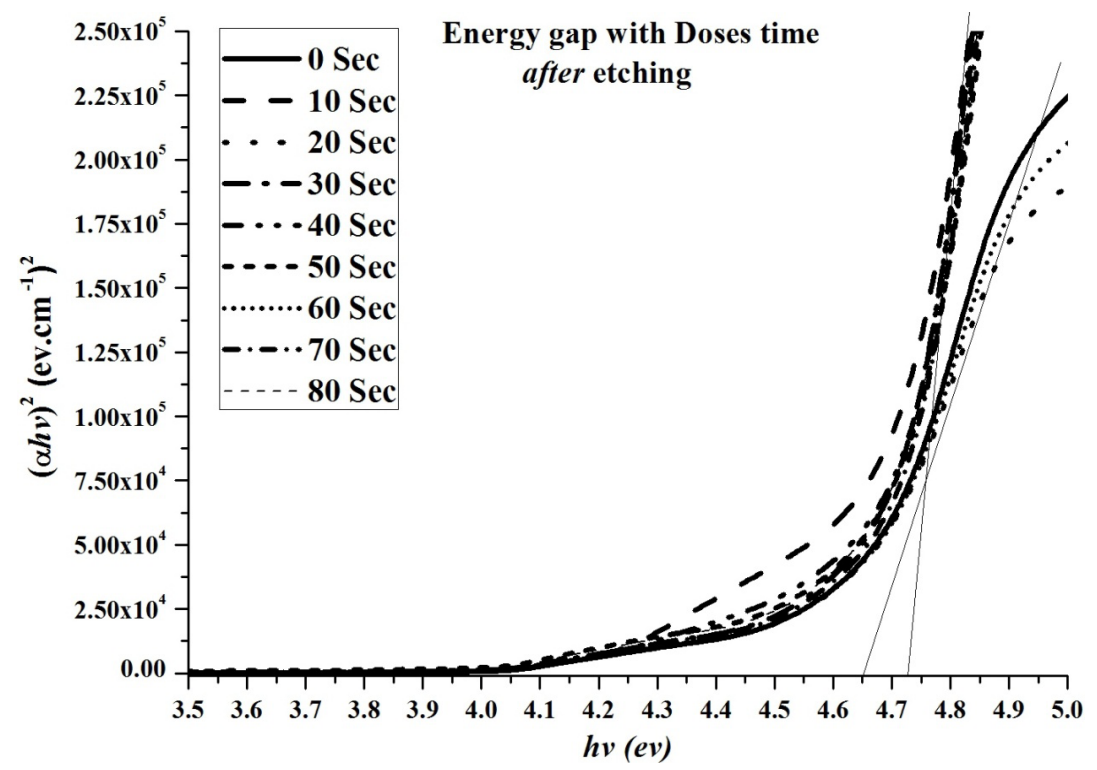

Figure 7: Optical energy gap of the pristine and the irradiated detectors after etching. 


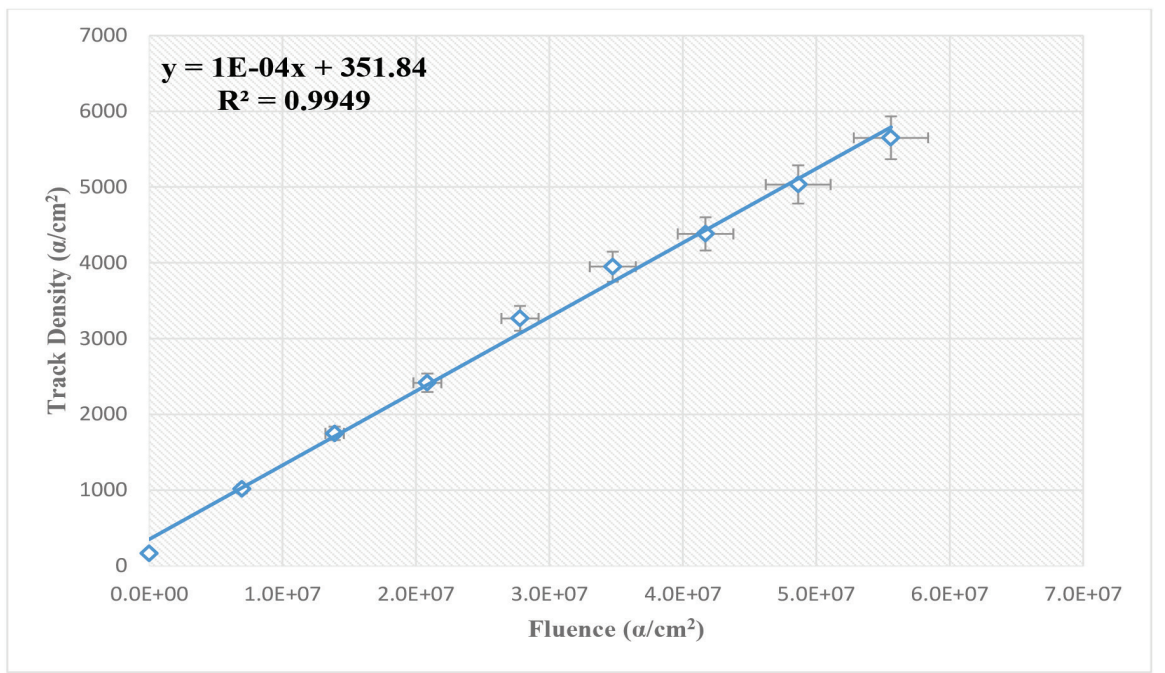

Figure 8: Correlation between track density measurements after etching and affluence calculations.

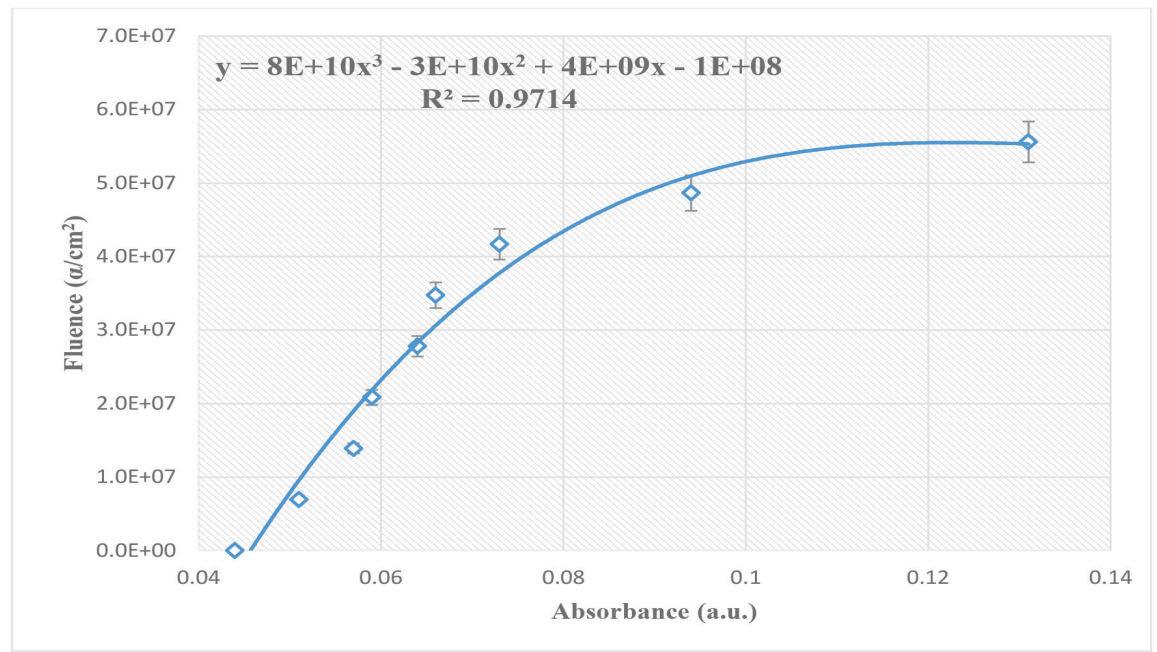

Figure 9: Correlation between affluence calculations and measurements of absorbance at $650 \mathrm{~nm}$ after etching. 


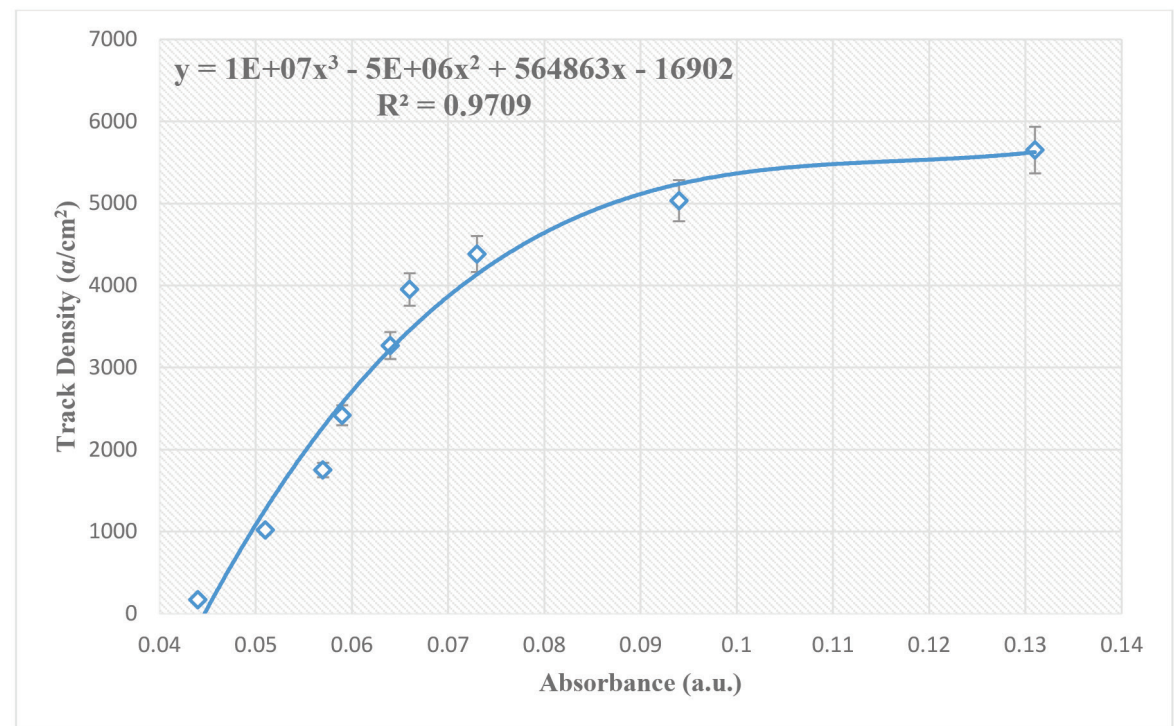

Figure 10: Relation between track density calculations with measurements of absorbance at $650 \mathrm{~nm}$ after etching.

\section{CONCLUSION}

This study indicated a good correlation between theoretical calculations for affluence of alpha particles and the experimental measurements of the track density (Equation 6). The best significance was confirmed with a high correlation coefficient $\mathrm{R}^{2}=0.995$. This work gives an easy method to calculate the track density emitted from any known activity of alpha source without using the solidstate nuclear track detectors by the semi-empirical equations founded in this study.

Also, the current study found that there is no relation between the irradiation times or track density with the absorbance in all wavelengths, except at a visible wavelength $(650 \mathrm{~nm})$, a high polynomial correlation in order 3 between the data points and the trend line $\left(\mathrm{R}^{2}=0.97\right)$ was noted after etching (Equation 7). A high correlation of the two equations can be used to the calculation of alpha or radon gas concentrations by the visible spectrum in $650 \mathrm{~nm}$ without using microscopic viewing (Equation 8). The semi-empirical equations found in the present study are recommended to be used for the background or low concentrations of radon gas or alpha emitters (activity at $0-10 \mu \mathrm{Ci}$ ). 


\section{ACKNOWLEDGEMENTS}

The authors wish to thank all team members in the Material and Radioactivity Laboratory at the College of Science, Mustansiriyah University, Iraq for their support.

\section{REFERENCES}

1. Zaki, M. F. (2008). Gamma-induced modification on the optical band gap of CR-39 SSNTD. Braz. J. Phys., 38(4), 558-562, https://doi.org/10.1590/S010397332008000500005.

2. Abdelrazek, E. M. et al. (2010). The influence of gamma-irradiation on some physical properties of chlorophyll/PMMA film. Appl. Surf. Sci., 256(9), 27112718, https://doi.org/10.1016/j.apsusc.2009.11.044.

3. Nouh, S. A. et al. (2005). Modification of thermal, optical and structural properties of bayfol nuclear track detector by alpha particles irradiation. Rad. Meas., 39(5), 471-477, https://doi.org/10.1016/j.radmeas.2004.10.007.

4. Farooq, W. A. et al. (2013). Controlling of optical band gap of allyl diglycol carbonate polymer with ultraviolet laser radiation. Acta Phys. Polon. A, 123(1), 106-110, https://doi.org/10.12693/APhysPolA.123.106.

5. Nikezic, D. \& Yu, K. N. (2004). Formation and growth of tracks in nuclear track materials. Mater. Sci. Eng. Rep., 46(3-5), 51-123, https://doi.org/10.1016/j. mser.2004.07.003.

6. Eissa, M. F. (2011). Optical properties of CR-39 track etch detectors irradiated by alpha particles with different energies. J. Mater. Sci. Eng., 5(1), 26-31.

7. Akram, E. et al. (2016). Study of structural and optical properties of new films derived PVC-2-[5-phenyl-1,3,4-thiadiazol-2-ylimino-methyl]-benzoic acid. RJPBCS, 7(5), 2836.

8. Saad, E. N. et al. (2014). Investigation of the physical properties of polymeric materials induced by alpha radiation. IJAR, 2(12), 694-702.

9. Al-Taii, H. M. J. (2013). Calculation the optical energy of LR-115 SSNTD irradiated by an alpha particle. Iraqi J. Phys., 11(22), 1-7. 